\title{
P04-9-21 Poster session
}

\section{Study of healing effects of irsogladine maleate-containing formulations for acetic acid-induced oral stomatitis in Syrian golden hamsters}

\author{
Mitsutoshi Satoh ${ }^{1}$, Atsune Kamada ${ }^{1}$, Ayano Imamura², Yayoi Kawano², Takehisa Hanawa² \\ ${ }^{I}$ Department of Toxicology and Pharmacology, Division of Pharmacy Practice, Meiji Pharmaceutical University, \\ Japan, ${ }^{2}$ Department of Clinical Pharmaceutical Preformulation, Faculty of Pharmaceutical Sciences, Tokyo University \\ of Science, Japan
}

Oral stomatitis is one of the adverse events induced by 5 -fluorouracil (5-FU). The healing effects of irsogladine maleate (IM), a therapeutic agent for stomach ulcer, were examined on oral stomatitis with 5-FU. The oral stomatitis model in the cheek pouch were produced by submucosal injection of $25 \mu \mathrm{L}$ of $10 \%$ acetic acid solution in male Syrian golden hamsters anesthetized with pentobarbital $30 \mathrm{mg} / \mathrm{kg}$ i.p. on day $-2.5-\mathrm{FU}$ was injected at $60 \mathrm{mg} / \mathrm{kg} /$ day i.p. on days -4 and -2 . In the IM application group, $0.2 \mathrm{~mL}$ of IM solution or vehicle was started from day 0 to the oral mucosa of the cheek pouch. Application of $1.2 \mathrm{mg} / \mathrm{mL}$ IM solution significantly reduced the areas of injury in 5-FU-untreated animals. Application of $1.2 \mathrm{mg} / \mathrm{mL}$ IM suspension in sodium carboxymethylcellulose (CMC-Na) solution did not reduce the area of oral injury in this model, and no reduction was observed upon p.o. administration of 1.2 and $4.0 \mathrm{mg} / \mathrm{mL}$ IM solution. The areas of oral injury in 5-FU-treated animals were significantly larger than those in 5-FU-untreated animals. The period required for the area of oral injury to be reduced to $50 \%$ was about 4.9 and 3.9 days in the 5 -FU-treated and -untreated animals, respectively. Application of $4.0 \mathrm{mg} / \mathrm{mL}$ IM solution significantly reduced the area of injury in the 5 -FU-treated animals. In addition, $4.0 \mathrm{mg} / \mathrm{mL}$ IM in a solution containing gum ghatti to increase viscosity and retention reduced the area of oral injury significantly. However, p.o. administration of 1.2 or $4.0 \mathrm{mg} / \mathrm{mL}$ IM in gum ghatti-containing solution had no reduction effects. These results suggest that application of IM reduces the area of oral injury in acetic acid-induced oral stomatitis developing under both 5-FU-treated and -untreated conditions. 